\title{
A new resource to summarize evidence on immunization from the Canadian Vaccination Evidence Resource and Exchange Centre (CANVax)
}

\author{
Noni E MacDonald ${ }^{1 *}$, Eve Dubé2
}

\begin{abstract}
Scientific progress around the development, use and best practices for communicating the benefits of vaccines is rapid, and keeping up-to-date with the substantial body of evidence on these topics is challenging. However, the increase in the number of vaccines and decline in vaccine-preventable illnesses has often focused public attention more on the risks of vaccines rather than the risks of the diseases. In Canada and elsewhere, an increasing number of parents are choosing to delay and/or refuse some or all vaccines for their children, leading to declining community protection against vaccine-preventable diseases and an increase in the number of outbreaks of vaccine-preventable diseases. Evidence suggests that the concept of vaccine hesitancy contributes to a deeper understanding of vaccination decisions by moving beyond the traditional binary of pro- or anti-vaccine attitudes to recognize a spectrum of beliefs and associated behaviours that occupies the space between the two poles. At a time of growing antimicrobial resistance to infections, protection conferred by vaccination is more important than ever.
\end{abstract}

The Canadian Vaccination Evidence Resource and Exchange Centre (CANVax) is an online curated database of resources to support immunization and promotional activities aimed at improving vaccine acceptance and uptake in Canada. It includes both the identification of accurate and reliable resources and the creation of new resources by a group of multidisciplinary professionals.

This issue of the Canada Communicable Disease Report (CCDR) includes the first of a series of "CANVax Briefs" that have been developed by experts after conducting scoping reviews and environmental scans and assessing the most rigorous evidence. The aim of the CANVax Briefs is to bring attention to current and emerging issues by providing short summaries of the recent best available evidence to assist frontline public health and clinical care professionals in optimizing the immunization rate in Canada. CANVax Briefs will be published in CCDR throughout 2020.

Suggested citation: MacDonald NE, Dubé E. A new resource to summarize evidence on immunization from the Canadian Vaccination Evidence Resource and Exchange Centre (CANVax). Can Commun Dis Rep 2020;46(1): 16-9. https://doi.org/10.14745/ccdr.v46i01a03

Keywords: immunization, vaccine hesitancy, evidence-based policy, vaccine-preventable outbreaks, CANVax

\section{Introduction}

Scientific progress around the development and use of vaccines has been rapid over the past 40 years (1). In Canada, the number of vaccines included in the publicly funded vaccination program for children from birth to 18 years of age has more than tripled since 1980, from eight to 17 antigens by 2019 (2). Not only has the number of vaccines risen, but the number of immunizations given in a single visit has also increased. For example, up to four different vaccines may be given in a single childhood vaccination visit depending on the provincial and territorial vaccination program (3).

\section{*Correspondence: \\ noni.macdonald@dal.ca}

\begin{abstract}
This work is licensed under a Creative Commons Attribution 4.0 International License.

Affiliations

1 Department of Paediatrics Dalhousie University, IWK Health Centre Halifax, NS

${ }^{2}$ Quebec National Institute of Public Health, Quebec City, QC
\end{abstract}


As vaccine schedules grow increasingly complex so do the needs and expectations of patients and health care providers concerning vaccine safety and effectiveness. For some, the increase in the number of vaccines and decline in vaccinepreventable illnesses has focused more attention on the risks of the vaccines rather than the risks of the diseases (4). In Canada and elsewhere, an increasing number of parents are choosing to delay and/or refuse some or all vaccines for their children, leading to declining community protection against vaccinepreventable diseases and major outbreaks of those diseases (5-9). Sadly, reported uptake rates in Canada are falling short of national and international targets (10).

In Canada approximately $15 \%$ to $20 \%$ of parents are concerned about accepting vaccines for their children, with some deciding to delay, postpone or even refuse some or all vaccines $(5,11,12)$. Given that vaccine-hesitant parents are not uniformly spread across the population but frequently cluster geographically due to common values and lifestyle, we now have fertile grounds for major outbreaks of vaccine-preventable diseases (7-9).

The recent increase in vaccine-preventable outbreaks occurred at the same time as rising rates of antimicrobial resistance. Antimicrobial resistance threatens the effective prevention and treatment of an ever-increasing number of infections (13). In 2019, the World Health Organization identified antimicrobial resistance and vaccine hesitancy as two of the top 10 threats to global health (14), making the optimization of vaccination rates more important than ever.

In this editorial, we identify vaccine hesitancy as including a number of concerns; describe the Canadian Vaccination Evidence Resource and Exchange Centre (CANVax), a new resource that provides curated information on vaccines for frontline public health and clinical care as well as other educational services; and introduce a series of CANVax Briefs that will be published in the Canada Communicable Disease Report (CCDR) throughout 2020, starting with this issue.

\section{Vaccine hesitancy}

Vaccine hesitancy, or the "delay in acceptance or refusal of vaccine despite the availability of vaccination services" (12), is receiving increasing international attention. The scope of vaccine hesitancy includes instances where "vaccine acceptance in a specific setting is lower than would be expected, given the availability of vaccination services" (12).

The concept of vaccine hesitancy contributes to a deeper understanding of vaccination decisions by moving beyond the traditional binary of pro- or anti-vaccine attitudes to recognize a spectrum of beliefs and associated behaviours that occupies the space between the two poles. A vaccine-hesitant person can delay, be reluctant but still accept, or refuse one, some or all vaccines.
Vaccination decisions are complex and multidimensional, and can be very vaccine-specific.

At the individual level, reviews have focused on factors associated with vaccine acceptance or refusal, identifying determinants such as:

- Fear of side effects

- Perceptions around health and prevention of disease

- A preference for "natural" health

- Low perception of the efficacy and usefulness of vaccines

- Negative past experiences with vaccination services

- A lack of awareness or knowledge about vaccination (4)

The World Health Organization summarizes the diverse factors leading to vaccine hesitancy into three broad categories (12):

- Complacency: Perceived risks of vaccine-preventable diseases are low and vaccination is not deemed necessary

- Convenience: The real and/or perceived quality of the service and the degree to which vaccination services are delivered at a time and place and in the cultural context that are convenient and comfortable

- Confidence: Trust in the effectiveness and safety of vaccines; in the system that delivers them, including the reliability and competence of the health services and health professionals; and in the motivations of the policy-makers who decide which vaccines are needed when and where

The growing interest in vaccine hesitancy-and vaccine acceptance more broadly-has generated an increasing number of publications. Keeping up-to-date with the substantial body of peer-reviewed research and major domestic and international reports relevant to vaccine acceptance and uptake that are being produced can be challenging.

\section{CANVax}

CANVax is a new online curated database of resources to support immunization program planning and promotional activities aimed at improving vaccine acceptance and uptake in Canada (15). CANVax has been developed by the Canadian Public Health Association (CPHA) with funding from the Public Health Agency of Canada. It includes curated resources from Canada and around the world, interactive features, educational updates and new resources. CANVax is now a member of Vaccine Safety Net, the World Health Organization global network of vetted websites that provide reliable information on vaccine safety (16).

\section{Curated resources}

CANVax houses a collection of selected evidence-based products and resources to make it easier for public health professionals to access and gather resources to inform their planning and activities. It includes a large database that covers five broad areas: vaccine decision making; monitoring and surveillance; vaccine safety and development; program 
planning and delivery; and policy. In each area there are multiple topics, and for each topic there are resources on background knowledge, implementation tools and evidence and key influencers or leaders in the field. (Table 1).

\section{Table 1: Summary of the subject areas and topics in CANVax's curated database}

\begin{tabular}{|c|c|c|}
\hline $\begin{array}{l}\text { Subject } \\
\text { areas }\end{array}$ & Topics & Resources \\
\hline \multirow{6}{*}{$\begin{array}{l}\text { Vaccine } \\
\text { decision } \\
\text { making }\end{array}$} & \multirow{3}{*}{ Vaccine hesitancy } & $\begin{array}{l}\text { Understanding hesitancy and } \\
\text { vaccine decision making }\end{array}$ \\
\hline & & Misconceptions \\
\hline & & $\begin{array}{l}\text { Complementary and alternative } \\
\text { medicine }\end{array}$ \\
\hline & \multirow{3}{*}{ Vaccine acceptance } & $\begin{array}{l}\text { Understanding vaccine } \\
\text { acceptance and uptake }\end{array}$ \\
\hline & & Counselling and communication \\
\hline & & Anxiety and pain management \\
\hline \multirow{6}{*}{$\begin{array}{l}\text { Monitoring } \\
\text { and } \\
\text { surveillance }\end{array}$} & $\begin{array}{l}\text { Vaccine monitoring } \\
\text { and surveillance }\end{array}$ & Vaccination coverage and goals \\
\hline & \multirow{2}{*}{$\begin{array}{l}\text { Outbreaks and } \\
\text { pandemics }\end{array}$} & Outbreaks \\
\hline & & Influenza pandemics \\
\hline & \multirow{3}{*}{$\begin{array}{l}\text { Vaccine preventable } \\
\text { disease surveillance }\end{array}$} & $\begin{array}{l}\text { Provincial and territorial } \\
\text { surveillance }\end{array}$ \\
\hline & & National surveillance \\
\hline & & Global surveillance \\
\hline \multirow{4}{*}{$\begin{array}{l}\text { Vaccine } \\
\text { safety and } \\
\text { development }\end{array}$} & \multirow[b]{2}{*}{ Vaccine safety } & Vaccine safety \\
\hline & & $\begin{array}{l}\text { Adverse events following } \\
\text { immunization (AEFI) }\end{array}$ \\
\hline & \multirow{2}{*}{$\begin{array}{l}\text { Research and } \\
\text { development }\end{array}$} & Vaccine ingredients \\
\hline & & Vaccine development \\
\hline \multirow{7}{*}{$\begin{array}{l}\text { Program } \\
\text { planning and } \\
\text { delivery }\end{array}$} & \multirow{2}{*}{$\begin{array}{l}\text { Promotion and } \\
\text { communications }\end{array}$} & Marketing and campaigns \\
\hline & & Communications \\
\hline & \multirow{2}{*}{$\begin{array}{l}\text { Program delivery } \\
\text { and evaluation }\end{array}$} & Informed consent \\
\hline & & Clinics \\
\hline & $\begin{array}{l}\text { Vaccine } \\
\text { management }\end{array}$ & Storage and handling \\
\hline & $\begin{array}{l}\text { Outbreak and crisis } \\
\text { management }\end{array}$ & Crisis communications \\
\hline & $\begin{array}{l}\text { Professional } \\
\text { development }\end{array}$ & Education and training \\
\hline Policy & $\begin{array}{l}\text { Immunization } \\
\text { policies }\end{array}$ & $\begin{array}{l}\text { Mandatory immunization and } \\
\text { activities }\end{array}$ \\
\hline
\end{tabular}

Abbreviation: CANVax, Canadian Vaccination Evidence Resource and Exchange Centre

How does it work? CANVax is supported by a multidisciplinary group of experts with skills and knowledge in public health, infectious diseases, medical anthropology, paediatrics, internal medicine, sociology, information technology, social media and library science. This group reviews Canadian and international resources, products and tools prior to their inclusion on the CANVax website.

\section{Interactive features}

All users are able to download any resource. In addition, the following interactive features are available when a user registers with CANVax:

- Share - easily share a resource with colleague using social media or email

- Comment - provide feedback on resources you have used

- Save - bookmark the resource you need for easy and convenient access and save your search strategy for future reference

\section{Educational services}

In addition to posting curated resources, CANVax's monthly newsletter provides updates on new resources and highlight articles on emerging topics in immunization. CANVax's podcasts and webinars also focus on emerging topics, with experts from across Canada exploring emerging immunization issues and initiatives.

\section{CANVax Briefs}

CANVax is developing new resources to provide succinct summaries and highlights of key new research. "CANVax Briefs" are short evidence-based articles that aim to inform, engage and inspire readers by bringing attention to current and emerging issues in immunization, and by profiling initiatives and activities from across Canada that aim to improve vaccine acceptance and uptake.

In this issue, we begin a series of CANVax Briefs by focusing first on how vaccine hesitancy has been increasing with the availability of Web 2.0 and social media, that this hesitancy has been associated with an increase in outbreaks of vaccine-preventable diseases and then identify the best practices to address this (17). More Briefs will be published in subsequent issues of CCDR in 2020.

Topics for the Briefs are identified by the CANVax team. The team consists of CPHA staff and immunization experts, Dr. Noni MacDonald and Dr. Eve Dubé. Experts on the chosen subject are then invited to contribute to the development of the brief. Short scoping reviews of evidence are conducted and reviewed by the CANVax Expert Review Panel, which is made up of external experts in immunization (18).

\section{Conclusion}

Enormous evidence-based progress has been made to address the declining community protection against vaccine-preventable diseases that has been seen around the world. CANVax was created to help frontline practitioners remain abreast of these developments in order to promote and maintain higher immunization rates in Canada. One of the strengths of the CANVax website is it is interactive. CANVax welcomes feedback 
on its website and its products and is open to suggestions for specific topics to be covered in future CANVax Briefs and webinars. Check out the CANVax website for details.

\section{Authors' statement}

NM - Writing - original draft

ED - Writing - review and editing

\section{Conflict of interest}

Dr. MacDonald reports grants from the Public Health Agency of Canada, the Canadian Institutes of Health Research, Nova Scotia Health Authority, IWK Health Authority and the Canadian Immunization Research Network. Dr. Dubé reports grants from the Public Health Agency of Canada, the Quebec Ministry of Health and Social Services, le Fonds de la recherche en santé du Québec, the Canadian Institutes of Health Research, the Canadian Immunization Research Network, and the Social Sciences and Humanities Research Council of Canada. Both authors are members of the CANVax Team.

\section{Acknowledgements}

Production of the Canadian Vaccination Evidence Resource and Exchange Centre (CANVax) has been made possible through funding from the Public Health Agency of Canada. Many authors, committees, immunization partners and reviewers contribute to CANVax, and especially the CANVax secretariat at Canadian Public Health Association.

\section{References}

1. Bloom BR, Lambert PH, editors. The vaccine book, 2nd ed. Cambridge (MA): Academic Press; 2016.

2. Public Health Agency of Canada. Canadian immunization guide. Ottawa (ON): Government of Canada; 2018 (Accessed 2019-1103). https://www.canada.ca/en/public-health/services/canadianimmunization-guide.html

3. Canada's provincial and territorial routine (and catch-up) vaccination routine schedule programs for infants and children. Ottawa (ON): Government of Canada (Accessed 2019-11-03). https://www.canada.ca/en/public-health/services/provincialterritorial-immunization-information/provincial-territorial-routinevaccination-programs-infants-children.html

4. Dubé E, Laberge C, Guay M, Bramadat P, Roy R, Bettinger J. Vaccine hesitancy: an overview. Hum Vaccin Immunother 2013 Aug;9(8):1763-73. DOl PubMed
5. Dubé $E$, Gagnon D, Ouakki M, Bettinger JA, Witteman HO, MacDonald S, Fisher W, Saini V, Greyson D; Canadian Immunization Research Network. Measuring vaccine acceptance among Canadian parents: A survey of the Canadian Immunization Research Network. Vaccine 2018 Jan;36(4):545-52. DOI PubMed

6. Lane S, MacDonald NE, Marti M, Dumolard L. Vaccine hesitancy around the globe: analysis of three years of WHO/UNICEF Joint Reporting Form data-2015-2017. Vaccine 2018 Jun;36(26): 3861-7. DOl PubMed

7. Wielders CC, van Binnendijk RS, Snijders BE, Tipples GA, Cremer J, Fanoy E, Dolman S, Ruijs W, Boot HJ, de Melker $\mathrm{HE}$, Hahné SJ. Mumps epidemic in orthodox religious low-vaccination communities in the Netherlands and Canada, 2007 to 2009. Euro Surveill 2011 Oct;16(41):19989. PubMed

8. Dubey V, Ozaldin O, Shulman L, Stuart R, Maclachlan J, Bromley $L$, Summers A. Investigation and management of a large community mumps outbreak among young adults in Toronto, Canada, January 2017-February 2018. Can Commun Dis Rep 2018 Dec;44(12):309-16. DOI PubMed

9. Kershaw T, Suttorp V, Simmonds K, St Jean T. Outbreak of measles in a non-immunizing population, Alberta 2013. Can Commun Dis Rep 2014 Jun;40(12):243-50. DOI PubMed

10. WHO-UNICEF. WHO vaccine-preventable diseases: monitoring system 2019 global summary. Geneva (CH): World Health Organization; 2019 (Accessed 2019-11-03). https://apps.who. int/immunization_monitoring/globalsummary/timeseries/ tswucoveragedtp3.html

11. Dubé $E$, MacDonald NE. Addressing vaccine hesitancy and refusal in Canada. CMAJ 2016 Jan;188(1):E17-8. DOI PubMed

12. MacDonald NE; SAGE Working Group on Vaccine Hesitancy. Vaccine hesitancy: Definition, scope and determinants. Vaccine 2015 Aug;33(34):4161-4. DOl PubMed

13. Antimicrobial resistance. Geneva $(\mathrm{CH})$ : World Health Organization; 2018 (Accessed 2019-11-03). https://www.who.int/ news-room/fact-sheets/detail/antimicrobial-resistance

14. Ten threats to global health in 2019. Geneva (CH): World Health Organization; 2019 (Accessed 2019-11-03). https://www.who.int/ emergencies/ten-threats-to-global-health-in-2019

15. The Canadian Vaccination Evidence Resource and Exchange Centre. Ottawa (ON): CANVax; (Accessed 2019-11-03). https:// www.canvax.ca/

16. About Vaccine Safety Net. Geneva (CH): World Health Organization; (Accessed 2019-11-03). https://www. vaccinesafetynet.org/vsn/vaccine-safety-net

17. MacDonald NE, Dubé E. Promoting immunization resiliency in the digital information age. Can Commun Dis Rep 2020;(46):204. DOI

18. CANVax's expert review panel. Ottawa (ON): CANVax; (Accessed 2019-11-03). https://canvax.ca/canvaxs-expert-reviewpanel 